\title{
COMMUNICATION
}

Cite this: DOI: $10.1039 /$ xoxxooooox

Accepted ooth January 2012

DOI: $10.1039 /$ xoxxooooox

www.rsc.org/

\section{Mechanochemical C-H Bond Activation: Rapid and Regioselective Double Cyclopalladation Monitored by in situ Raman Spectroscopy $\dagger$}

\author{
Marina Juribašića ${ }^{\ddagger}$, Krunoslav Užarevića ${ }^{\ddagger}$, Davor Gracina ${ }^{\mathrm{a}}$, and Manda Ćurića ${ }^{*}$
}

The first direct mechanochemical transition-metal-mediated activation of strong phenyl $\mathrm{C}-\mathrm{H}$ bonds is reported. Mechanochemical procedure, resulting in cyclopalladated complexes, is quantitative and significantly faster than solution synthesis and allows highly regioselective activation of two $\mathbf{C}-\mathbf{H}$ bonds by palladium(II) acetate in asymmetrically substituted azobenzene. Milling is monitored by in situ solidstate Raman spectroscopy and in combination with quantumchemical calculations enabled characterization of involved reaction species, direct insight into the dynamics and reaction pathways, as well as the optimization of a milling process.

Cyclometalation via the transition-metal-mediated activation of carbon-hydrogen $(\mathrm{C}-\mathrm{H})$ bond is the simplest and the most common method for the formation of a metal-carbon $(\mathrm{M}-\mathrm{C}) \sigma$ bond. ${ }^{1}$ After the first reports in the middle $1960 \mathrm{~s}^{2}$ the $\mathrm{C}-\mathrm{H}$ activation process remains the most straightforward method for preparation of cyclometalated compounds which are widely used in organic synthetic chemistry for the insertion of various functionalities into hydrocarbons. ${ }^{3}$ Among them, cyclopalladated compounds have been studied most extensively not only for their wide application in organic synthesis and catalysis, but also due to their mesogenic, bioactive and photoluminescent properties. ${ }^{1 a, 1 c, 4}$ The synthesis of all known metalacycles relies exclusively on solvent-based techniques which may require elevated temperatures, toxic solvents (benzene, toluene, chloroform) and are often time-consuming. . $^{\mathrm{a}, 1 \mathrm{c}, 4}$

During the last decade mechanochemical reactions emerged as a viable and environmentally-friendly alternative to solvent-based techniques. ${ }^{5}$ Apart from the processing of inorganic materials, ${ }^{6}$ mechanosynthesis has been recognized as a rapid, selective and atom- and energy-efficient pathway to various classes of compounds

Ruđer Bošković Institute, Bijenička 54, HR-10000 Zagreb, Croatia E-mail:curic@irb.hr

$\dagger$ Electronic Supplementary Information (ESI) available: Experimental and computational details. CCDC 1005635-1005636 For ESI and crystallographic data in CIF or other electronic format see DOI: $10.1039 / \mathrm{c} 4 \mathrm{cc} 04423 \mathrm{a}$

‡ These authors contributed equally to this work. ranging from organic molecules ${ }^{7}$ and cocrystals ${ }^{8}$ up to metal-organic coordination compounds. ${ }^{9}$ Despite its wide application in different areas of chemistry, solid-state synthesis of organometallic compounds by direct formation of a $\mathrm{M}-\mathrm{C} \sigma$ bond has not been reported yet.

Here we describe the first example of palladium-mediated solidstate $\mathrm{C}-\mathrm{H}$ bond activation in asymmetrically substituted azobenzene 1, achieved by mechanochemical milling process (Scheme 1). The palladation of 1 proved to be regioselective, producing regioisomer $\mathbf{1 A}$ in higher yield and much faster than the analogous reaction in solution, with the reduction of solvent volume more than 10000 times. Further reaction of $\mathbf{1 A}$ with palladium(II) acetate $\left(\mathrm{Pd}(\mathrm{OAc})_{2}\right)$ leads to the second $\mathrm{C}-\mathrm{H}$ bond activation forming in a quantitative yield the doubly palladated complex 1B, which could not be obtained by conventional solution procedures. Milling reactions were monitored in situ and in real time by solid-state Raman spectroscopy, which was in combination with the quantum-chemical calculations employed for the interpretation of the reaction course on the molecular level.

Liquid-assisted grinding (LAG) ${ }^{5 \mathrm{a}, 8}$ of $4^{\prime}$-( $N, N$-dimethylamino)4-nitroazobenzene $(\mathbf{1})$ and $\mathrm{Pd}(\mathrm{OAc})_{2}$ with glacial acetic acid as an additive resulted in dimeric mono- $(\mathbf{1 A})$ and dicyclopalladated (1B)

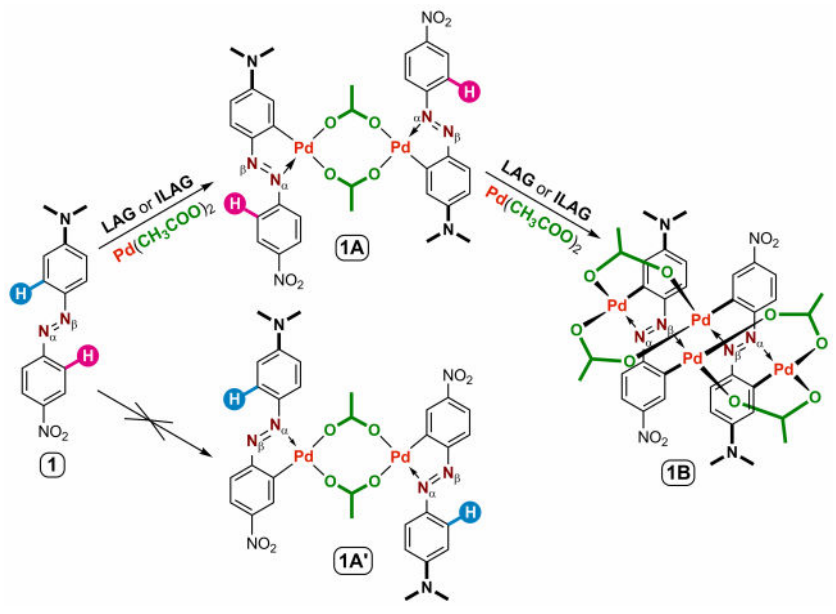

Scheme 1. Solid-state $\mathrm{C}-\mathrm{H}$ bond activation in azobenzene. 
complexes, Scheme $1 .{ }^{9}$ When the Pd(II) to azobenzene molar ratio was $1: 1$, the reaction produced monopalladated complex $\mathbf{1 A}$ in a quantitative yield with a higher reaction rate $(4.5 \mathrm{~h})$ and ten thousand times less solvent volume $(25 \mu \mathrm{L})$ than analogous reaction in solution (3 days and $250 \mathrm{~mL}$ ). Addition of two equivalents of $\mathrm{Pd}(\mathrm{OAc})_{2}$ and $25 \mu \mathrm{L}$ of glacial acetic acid to the product $1 \mathbf{A}$ led to the dicyclopalladated complex 1B within $7.5 \mathrm{~h}$. The same product could be obtain by LAG of 1 with an excess of $\mathrm{Pd}(\mathrm{OAc})_{2}$ in a quantitative yield via complex $\mathbf{1 A}$ as an intermediate. All attempts to obtain complex 1B in solution were unsuccessful, with reactions yielding exclusively 1A. Since solution-based palladations are often carried out using $\mathrm{Pd}(\mathrm{OAc})_{2}$ and sodium acetate in acetic acid, ${ }^{4 a}$ we have employed the ion-and-liquid-assisted grinding (ILAG) ${ }^{11}$ of $\mathrm{Pd}(\mathrm{OAc})_{2}$ and 1 with sodium acetate and acetic acid as additives. ILAG reactions resulted in formation of the same products at rates comparable to the LAG reaction. The presence of an excess of $\mathrm{Pd}(\mathrm{OAc})_{2}$ accelerated all reactions. The resulting mixtures were purified by washing with a small amount of water and tetrahydrofurane (THF) lowering quantitative yields to $78 \%$ (1A) and $85 \%(\mathbf{B B})^{9}$ The neat grinding synthesis (without any additives) were also performed. Reactions were very slow (more than $10 \mathrm{~h}$ for $\mathbf{1 A}$ or $20 \mathrm{~h}$ for $\mathbf{1 B}$ ) and all attempts to obtain $\mathbf{1 A}$ and $\mathbf{1 B}$ without impurities (reactants) were unsuccessful. The purity of products was determined by combining IR and Raman spectroscopies in solid state with the ${ }^{1} \mathrm{H}$ NMR spectroscopy in solution. The ${ }^{1} \mathrm{H}$ NMR, IR, Raman and luminescence spectra of the milling product $\mathbf{1 A}$ and that obtained from solution were in an excellent agreement (Electronic Supplementary Information).

Single crystals of $\mathbf{1 A}$ and $\mathbf{1 B}$ were prepared by recrystallization of milling products from $N, N$ dimethylformamide and $\mathrm{CH}_{2} \mathrm{Cl}_{2} / \mathrm{THF}$ mixture, respectively. Both complexes are anti dimers with transoid (1A) or cisoid (1B) geometry in which each palladium atom is bonded in a slightly distorted square-planar geometry to one carbon atom of the phenyl ring, one azo-nitrogen, and two oxygen atoms of the bridging acetate ligands mutually in cis position, Fig. 1. Palladium atoms in $\mathbf{1 A}$ can be bound either to alpha or to beta nitrogen producing alpha or beta isomers ${ }^{12}$ and each of them can adopt cisoid and transoid geometry with a syn or anti orientation of substituents, Scheme $1 .^{1 \mathrm{a}, 4 \mathrm{a}}$ The isolated complex $\mathbf{1 A}$ is an alpha isomer and its molecular structure is dimeric with two monocyclopalladated azobenzene units bonded by two bridging acetate ligands in an anti open-book arrangement, Fig. 1. The molecular structure of $\mathbf{1 B}$ corresponds to a centrosymmetric tetranuclear acetato-bridged complex. It is a

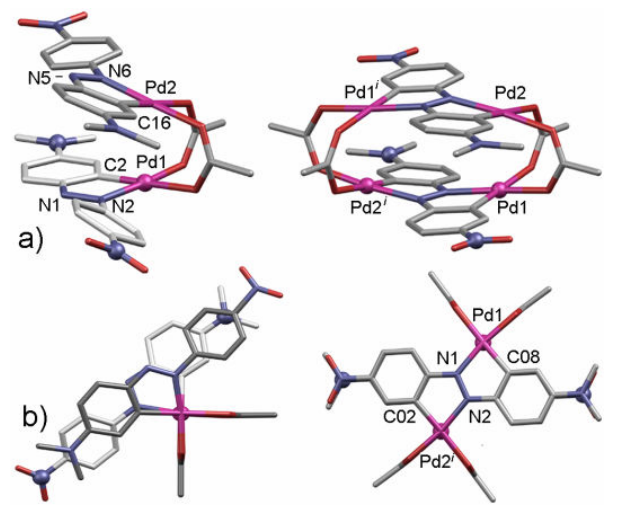

Fig. 1. a) Side-view of $\mathbf{1 A}$ (left) and $\mathbf{1 B}$ (right); b) top-view of $\mathbf{1 A}$ and 1B. Molecule 1B is centrosymmetric with a symmetry operator $[-x, 1-y$, $1-z]$ generating the other half of the molecule. Solvent molecules and hydrogen atoms are omitted for clarity.

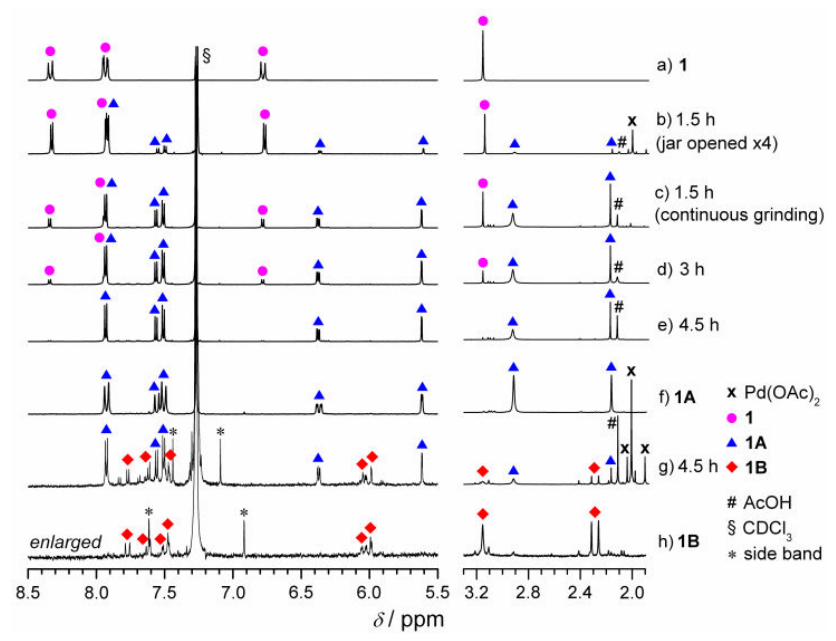

Fig. 2. ${ }^{1} \mathrm{H}$ NMR spectra (in $\mathrm{CDCl}_{3}$ ) of a) ligand $\mathbf{1}$; b) LAG reaction of $\mathbf{1}$ and $\mathrm{Pd}(\mathrm{OAc})_{2}$ after $1.5 \mathrm{~h}$ with opening the jar 4 times; reaction mixtures

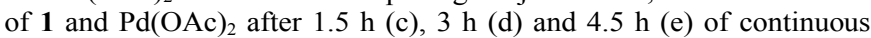
$\mathrm{LAG} ; \mathrm{f}$ ) isolated $\mathbf{1 A} ; \mathrm{g})$ reaction mixture of $\mathbf{1 A}$ and $\mathrm{Pd}(\mathrm{OAc})_{2}$ in excess after $4.5 \mathrm{~h}$ of continuous LAG; and h) isolated $\mathbf{1 B}$.

unique dimer with two dicyclopalladated azobenzene units forced to lie exactly above one another by four cis-bonded acetate ligands, Fig. $1 b$.

The stepwise ex situ NMR monitoring of the milling mixtures during LAG reactions of $\mathbf{1}$ and $\mathrm{Pd}(\mathrm{OAc})_{2}$ (Fig. 2) revealed the presence of reactants, products $(\mathbf{1 A}$ or $\mathbf{1 B})$ and low concentrations of species tentatively assigned as coordination intermediates, adduct or cyclopalladated adduct, from which $\mathrm{C}-\mathrm{H}$ bond activation starts in the mono- or dicyclopalladation. ${ }^{12 a}$ NMR studies clearly demonstrated that the formation of complex 1B proceeds through complex $\mathbf{1 A}$ as an intermediate. The presence of one set of signals in the ${ }^{1} \mathrm{H}$ NMR spectra of both complexes confirmed the formation of just one (regio)isomer in each reaction. Collecting the samples of reaction mixture several times within the first 90 minutes slowed down the reactions of $\mathbf{1}$ and $\mathrm{Pd}(\mathrm{OAc})_{2}$ as compared to the uninterrupted 90-minute-reactions probably due to acetic acid evaporation (Fig. 2). This clearly indicated that the stepwise ex situ analysis disturbed reaction conditions. ${ }^{12}$

To gain the direct insight in the reaction profile, the new in situ Raman spectroscopic technique ${ }^{13 a}$ was used to directly monitor mono- and dicyclopalladation in solid state without interrupting the milling process. The major changes in the Raman spectra during the milling reactions were observed in $1000-1600 \mathrm{~cm}^{-1}$ region, Figs. 3 and 4. Raman spectra assignment was done on the basis of literature data $^{14}$ and quantum-chemical calculations ${ }^{15}$ (Fig. 3). Less informative phenyl ring vibrations were not included in this spectral analysis due to their coupling with the vibrations of other functional groups.

Raman monitoring of the LAG reaction of $\mathrm{Pd}(\mathrm{OAc})_{2}$ and 1 indicated that the monopalladated complex $\mathbf{1 A}$ was formed within ca. $4 \mathrm{~h}$, Fig. 4a. On the molecular level, the first cyclopalladation reaction produced a five-membered palladacycle upon coordination of the palladium to the azo-nitrogen and formation of the $\mathrm{Pd}-\mathrm{C}$ bond, Scheme 1. Raman studies showed a large shift (up to $138 \mathrm{~cm}^{-}$ ${ }^{1}$ ) of several bands assigned to the $\mathrm{N}=\mathrm{N}$ stretching coupled with $v_{\text {sym }}\left(\mathrm{NO}_{2}\right)$ and/or phenyl ring vibrations of 1 in the $1300-1390 \mathrm{~cm}^{-1}$ range, Fig. 4a. These bands diminished creating a new 


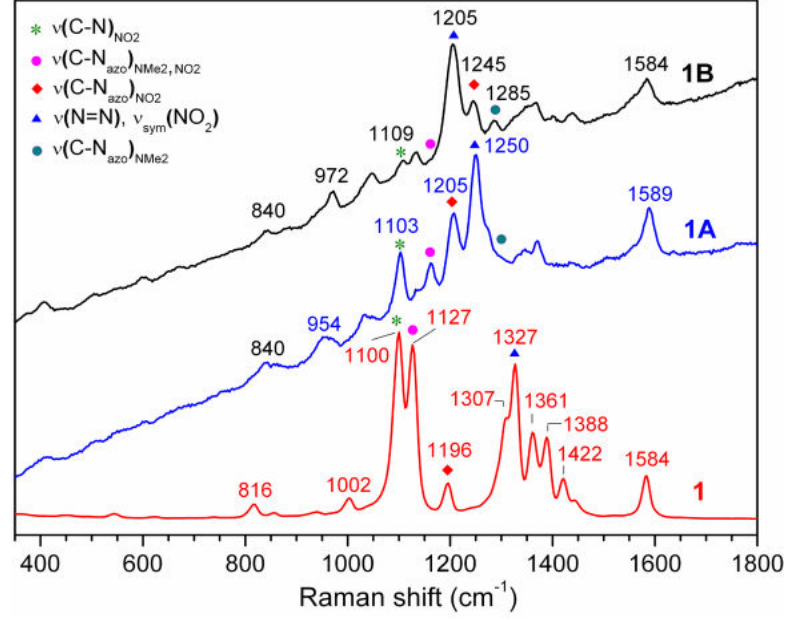

Fig. 3. Raman spectra of ligand $\mathbf{1}$ and its complexes $\mathbf{1 A}$ and $\mathbf{1 B}, \lambda_{\mathrm{exc}}=784$ $\mathrm{nm}$

$v(\mathrm{~N}=\mathrm{N}) / v_{\text {sym }}\left(\mathrm{NO}_{2}\right)$ combination band located at $1250 \mathrm{~cm}^{-1}$ in the spectrum of complex 1A. This observed large shift was associated with the considerable weakening of the $\mathrm{N}=\mathrm{N}$ bond due to the ring closing, leading also to its significant elongation to $1.29 \AA$ in $\mathbf{1 A}$ if compared to $1.26 \AA$ in $\mathbf{1}$, Table S5. Simultaneous strengthening of the $\left(\mathrm{C}-\mathrm{N}_{\mathrm{azo}}\right)_{\mathrm{NMe} 2}$ bond included in the formed palladacyle ring resulted in its shortening from 1.40 in $\mathbf{1}$ to $1.35 \AA$ in $\mathbf{1 A}$, and was accompanied by a shift of the band assigned to the stretching vibration of both $\mathrm{C}-\mathrm{N}_{\mathrm{azo}}$ bonds, $v\left(\mathrm{C}-\mathrm{N}_{\mathrm{azo}}\right)_{\mathrm{NMe} 2, \mathrm{NO} 2}$, from 1127 to $1160 \mathrm{~cm}^{-1}$. The small $v\left(\mathrm{C}-\mathrm{N}_{\mathrm{azo}}\right)_{\mathrm{NO} 2}$ band shift from $1196(\mathbf{1})$ to 1205 $\mathrm{cm}^{-1}$ (1A) was nicely correlated with the almost unchanged $(\mathrm{C}-$ $\left.\mathrm{N}_{\mathrm{azo}}\right)_{\mathrm{NO} 2}$ bond length $(1.41 \AA$ ) $)$. These observations indicated that $(\mathrm{C}-$ $\left.\mathrm{N}_{\mathrm{azo}}\right)_{\mathrm{NO2}}$ bond was not included in the newly formed ring and thus verified that the first palladation occurred regioselectively on the phenyl ring bearing the electron-donating substituent $\mathrm{NMe}_{2}$.

Raman monitoring definitely confirmed that LAG reaction of the 2:1 mixture of $\mathrm{Pd}(\mathrm{OAc})_{2}$ and $\mathbf{1 A}$ resulted in the formation of dicyclopalladated complex 1B after ca. $7 \mathrm{~h}$, Fig. $4 \mathrm{~b}$. The product of the second palladation reaction (1B) is highly delocalized molecule with four fused rings, $i$. e. two phenyl rings and two five-membered palladacycles, Scheme 1. These structural features render the positions of $v\left(\mathrm{C}-\mathrm{N}_{\mathrm{azo}}\right)_{\mathrm{NMe} 2, \mathrm{NO} 2}$ and $v(\mathrm{~N}=\mathrm{N}) / v_{\mathrm{sym}}\left(\mathrm{NO}_{2}\right)$ vibration bands as the most pronounced differences in the Raman spectra of complexes $\mathbf{1 A}$ and 1B, Fig. 3. The palladation of the nitrophenyl ring of $1 \mathrm{~A}$ was accompanied by shortening of the $\left(\mathrm{C}-\mathrm{N}_{\mathrm{azo}}\right)_{\mathrm{NO} 2}$ bond (by ca. $0.02 \AA)$ and induced the shift of the $v\left(\mathrm{C}-\mathrm{N}_{\mathrm{azo}}\right)_{\mathrm{NMe} 2, \mathrm{NO} 2}$ and $v\left(\mathrm{C}-\mathrm{N}_{\mathrm{azo}}\right)_{\mathrm{NO} 2}$ bands to higher energies by ca. $40 \mathrm{~cm}^{-1}$. Significantly smaller shift of the $v(\mathrm{~N}=\mathrm{N})$ band (from 1250 to $1205 \mathrm{~cm}^{-1}$ ) than in the first reaction (with the observed shift up to $138 \mathrm{~cm}^{-1}$ ) agrees with a slight elongation of the $\mathrm{N}=\mathrm{N}$ bond already involved in one palladacycle ring.

In addition to the valuable chemical information about the reaction course, Raman technique revealed strong luminescence ${ }^{16}$ of both cyclopalladated products in the IR region with emission maxima of $\mathbf{A}$ and $\mathbf{1 B}$ in different positions, Fig. S6. As the changes in the Raman spectra during in situ monitoring of both palladation reactions became less obvious, this phenomenon allowed unambiguous detection of the reaction completion.

It is interesting to note that the reaction rates of solid-state monoand dicyclopalladation of 1 by $\mathrm{Pd}(\mathrm{OAc})_{2}$ qualitatively follow the same trend as those determined for reactions of $\mathrm{Pd}(\mathrm{MeCN})_{2} \mathrm{Cl}_{2}$ and $\mathbf{1}$
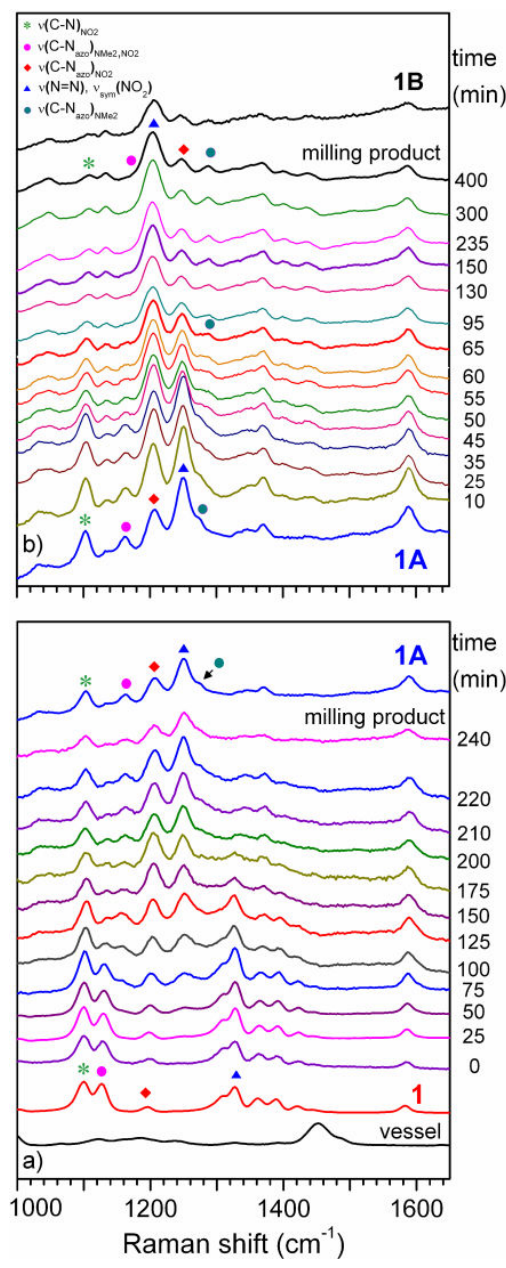

Fig. 4. Time-resolved Raman spectra of LAG reaction mixture of a) 1 and $\mathrm{Pd}(\mathrm{OAc})_{2}$ in molar ratio $1: 1$ and reaction mixture of $\left.\mathbf{b}\right) \mathbf{1} \mathbf{A}$ and $\mathrm{Pd}(\mathrm{OAc})_{2}$ in the molar ratio 1:2.

in solution. ${ }^{12 \mathrm{a}}$ The formation of monocyclopalladated complex $\mathbf{1 A}$ is almost three times faster than the formation of complex 1B (4 hours for 1A comparing to almost 12 hours needed for the formation of 1B).

In summary, ball milling was proved as a clean, regioselective and highly efficient synthetic method for the solid-state synthesis of organometallic compounds via $\mathrm{C}-\mathrm{H}$ bond activation by a $\mathrm{Pd}(\mathrm{II})$ precursor. The reaction profile and the formation of intermediates and cyclopalladated products as well as their luminescence properties have been monitored in situ and in real time by Raman spectroscopy, which allowed the direct optimization of the reaction conditions. The Raman monitoring revealed that the mechanochemical formation of dicyclopalladated complex proceeds over monocyclopalladated intermediate, which is a final product in the solution synthesis. We believe that the presented synthetic methodology may be applicable for the preparation of other organometallic compounds, in catalytic processes promoted by metals as well as in functionalization of the $\mathrm{C}-\mathrm{H}$ bond, without the limitations correlated with the solubility or stability of reaction components. Furthermore, presented results highlight in situ Raman spectroscopy in combination with computational methods as a powerful tool for the identification of intermediates and reaction products, and for gaining information about the course of milling reactions on molecular level. 
Authors would like to acknowledge Mr Željko Marinić for help with NMR measurements, Dr Ivan Halasz and Dr Marina Kveder for valuable discussions. The authors thank the Ministry of Science, Educations and Sports of the Republic of Croatia for financial support (grant nos. 098-0982915-2950 and 098-0982886-2894). The LS2 laser source used in this study was kindly donated by PD-LD Inc., Pennington, New Jersey (USA).

\section{Notes and references}

Ruđer Bošković Institute, Bijenička 54, HR-10000 Zagreb, Croatia E-mail:curic@irb.hr

Electronic Supplementary Information (ESI) available: Experimental and computational details. CCDC 1005635-1005636 For ESI and crystallographic data in CIF or other electronic format see DOI: $10.1039 / \mathrm{c} 4 \mathrm{cc} 04423 \mathrm{a}$

‡ These authors contributed equally to this work.

1 (a) M. Albrecht, Chem. Rev. 2010, 110, 576; (b) M. I. Bruce, Angew. Chem. Int. Ed. Engl. 1977, 16. 73; (c) I. Omae, Coord. Chem. Rev. 2004, 248, 995.

2 (a) A. C. Cope, R. W. Siekman, J. Am. Chem. Soc. 1965, 87, 3272; (b) J. P. Kleiman, M. Dubeck, J. Am. Chem. Soc. 1963, 85, 1544.

3 (a) A. McNally, B. Haffemayer, B. S. L. Collins, M. J. Gaunt, Nature, 2014, DOI: 10.1038/nature13389; (b) K. Godula, D Sames, Science, 2006, 312, 67; (c) T. W. Lyons, M. S. Sanford, Chem. Rev. 2010, 110, 1147; (d) L. Ackermann, Chem. Rev. 2011, 111, 1315; (e) J. Yamaguchi, A. D. Yamaguchi, K. Itami, Angew. Chem. Int. Ed. 2012, 51, 8960.

4 (a) J. Dupont, C. S. Consorti, J. Spencer, Chem. Rev. 2005, 105, 2527; (b) M. Ghedini, I. Aiello, A. Crispini, A. Golemme, M. La Deda, D. Pucci, Coord. Chem. Rev. 2006, 250, 1373; (c) M. Juribašić, I. Halasz, D. Babić, D. Cinčić, J. Plavec, M. Ćurić, Organometallics 2014, 33, 1227; (d) M. Juribašić, M. Ćurić, K. Molčanov, D. Matković-Čalogović, D. Babić, Dalton Trans. 2010, 39, 8769; (e) D. E. Bergbreiter, P. L. Osburn, Y. S. Liu, J. Am. Chem. Soc. 1999, 121, 9531; (f) A. C. F. Caires, Anti-Cancer Agents. Med. Chem. 2007, 7, 484; (g) Y. Wakatsuki, H. Yamazaki, P. A. Grutsch, M. Santhanam, C. Kutal, J. Am. Chem. Soc. $1985, \mathbf{1 0 7}, 8153$.

5 (a) S. L. James, C. J. Adams, C. Bolm, D. Braga, P. Collier, T. Friščić, F. Grepioni, K. D. M. Harris, G. Hyett, W. Jones, A Krebs, J. Mack, L. Maini, A. G. Orpen, I. P. Parkin, W. C. Shearouse, J. W. Steed, D. C. Waddell, Chem. Soc. Rev. 2012. 41, 413; (b) T. Friščić, Chem. Soc. Rev. 2012, 41, 3493.

6 V. Šepelak, A. Düvel, M. Wilkening, K.-D. Becker, P. Heitjans, Chem. Soc. Rev. 2013, 42, 7507; (b) R. Janot, D. Guerard, Prog. Mater. Sci. 2005, 50, 1; (c) E. Boldyreva, Chem. Soc. Rev. 2013, 42, 7719.

7 (a) G. Rothenberg, A. P. Downie, C. L. Raston, J. L. Scot, J. Am Chem. Soc. 2001, 123, 8701; (b) A. Stolle, T. Szuppa, S. E. S Leonhardt, B. Ondruschka, Chem. Soc. Rev. 2011, 40, 2317; (c) I. Huskić, I. Halasz, T. Friščić, H. Vančik, Green Chem. 2012, 14, 1597.

8 (a) D. Braga, L. Maini, F. Grepioni, Chem. Soc. Rev. 2013, 42, 7638; (b) T. Friščić, W. Jones, Cryst. Growth Des. 2009, 9, 1621.

9 All grinding experiments were performed at room temperature in a 14 mL PMMA jars using one $10 \mathrm{~mm}$ stainless steel grinding ball $(4 \mathrm{~g})$. A Retsch MM301 grinder mill operating at $30 \mathrm{~Hz}$ frequency was used for the synthesis. The complex $\mathbf{1 A}$ was prepared by liquid-assisted grinding (4.5 h) of $123.61 \mathrm{mg}$ of $\mathbf{1}$ and $121.28 \mathrm{mg}$ of $\mathrm{Pd}(\mathrm{OAc})_{2}$ in the presence of $25 \mu \mathrm{L}$ of acetic acid. The green powder was obtained in $78 \%$ yield after purification with small amounts of water and THF. The complex 1A was also prepared in a $39 \%$ yield by the solventbased reaction according to the previously reported procedure. ${ }^{4 \mathrm{~g}}$ The brown red powder of complex 1B was obtained by the same mechanochemical procedure within $7.5 \mathrm{~h}$ in a $85 \%$ yield using 97.19 $\mathrm{mg}$ of $1 \mathrm{~A}$ and $97.57 \mathrm{mg}$ of $\mathrm{Pd}(\mathrm{OAc})_{2}$.

10 (a) D. Cinčić, M. Juribašić, D. Babić, K. Molčanov, P. Šket, J. Plavec, M. Ćurić, Chem. Comm. 2011, 47, 11543; (b) W. Yuan, T. Friščić, D. Apperley, S. L. James, Angew. Chem. Int. Ed. 2010, 49, 3916; (c) A. L. Garay, A. Pichon, S. L. James, Chem. Soc. Rev. 2007, 36, 846.

11 T. Friščić, D. G. Reid, I. Halasz, R. S. Stein, R. E. Dinnebier, M. J. Duer, Angew. Chem. Int. Ed. 2010, 49, 712.

12 (a) M. Juribašić, A. Budimir, S. Kazazić, M. Curić, Inorg. Chem. 2013, 52, 12749; (b) D. Babić, M. Ćurić, K. Molčanov, G. Ilc, J. Plavec, Inorg. Chem. 2008, 47, 10446; (c) M. Ćurić, D. Babić, Ž. Marinić, Lj. Paša-Tolić, V. Butković, J. Plavec, Lj. Tušek-Božić, J. Organomet. Chem. 2003, 687, 85.

13 (a) D. Gracin, V. Štrukil, T. Friščić, I. Halasz, K.Užarević, Angew. Chem. Int. Ed. 2014, 53, 6193; (b) T. Friščić, I. Halasz, P. J. Beldon, A. M. Belenguer, F. Adams, S. A. J. Kimber, V. Honkimäki, R. E. Dinnebier, Nature Chem. 2013, 5, 66.

14 (a) N. Biswas, S. Umapathy, J. Phys. Chem. A 2000, 104, 2734; (b) G. Socrates, Infrared and Raman Characteristic Group Frequencies, 3rd ed. J. Wiley \& Sons, Chichester, 2001.

15 (a) Full geometry optimizations and vibrational calculations were performed using the B3LYP(ultrafine) method as implemented in the Gaussian09 program. ${ }^{15 \mathrm{~b}}$ The standard $6-311 \mathrm{G}^{* *}$ basis set was used for $\mathrm{C}, \mathrm{H}, \mathrm{N}$ and $\mathrm{O}$ atoms, whereas $\mathrm{Pd}$ atoms were modeled by the Stuttgart-Dresden (SDD) pseudopotential and the accompanying SDD basis set; (b) Gaussian 09, Revision D.01, M. J. Frisch, G. W. Trucks, H. B. Schlegel, G. E. Scuseria, M. A. Robb, J. R. Cheeseman, G. Scalmani, V. Barone, B. Mennucci, G. A. Petersson, H. Nakatsuji, M. Caricato, X. Li, H. P. Hratchian, A. F. Izmaylov, J. Bloino, G. Zheng, J. L. Sonnenberg, M. Hada, M. Ehara, K. Toyota, R. Fukuda, J. Hasegawa, M. Ishida, T. Nakajima, Y. Honda, O. Kitao, H. Nakai, T. Vreven, J. A. Montgomery, Jr., J. E. Peralta, F. Ogliaro, M. Bearpark, J. J. Heyd, E. Brothers, K. N. Kudin, V. N. Staroverov, R. Kobayashi, J. Normand, K. Raghavachari, A. Rendell, J. C. Burant, S. S. Iyengar, J. Tomasi, M. Cossi, N. Rega, J. M. Millam, M. Klene, J. E. Knox, J. B. Cross, V. Bakken, C. Adamo, J. Jaramillo, R. Gomperts, R. E. Stratmann, O. Yazyev, A. J. Austin, R. Cammi, C. Pomelli, J. W. Ochterski, R. L. Martin, K. Morokuma, V. G. Zakrzewski, G. A. Voth, P. Salvador, J. J. Dannenberg, S. Dapprich, A. D. Daniels, Ö. Farkas, J. B. Foresman, J. V. Ortiz, J. Cioslowski, and D. J. Fox, Gaussian, Inc., Wallingford CT, 2009.

16 (a) J. K. Grey, I. S. Butler, C. Reber, J. Am. Chem. Soc. 2002, 124, 9384; (b) J. K. Grey, I. S. Butler, C. Reber, Inorg. Chem. 2003, 42, 6503; (c) E. Pierce, E. Lanthier, C. Genre, Y. Chumakov, D. Luneau, C. Reber, Inorg. Chem. 2010, 49, 4901. 